\title{
Dr. Arthur A. Scott
}

\author{
Robert Byrick, MD (1)
}

Received: 7 May 2018/Accepted: 7 May 2018/Published online: 25 May 2018

(C) Canadian Anesthesiologists' Society 2018

After a lengthy illness, Dr. Arthur A. Scott passed away in Victoria, BC, on 14 April 2018. Arthur served as the fourth Chair of the Department of Anesthesia at the University of Toronto. He is survived by his wife, Sallie, herself an accomplished cardiac anesthesiologist, three children, and seven grandchildren.

Dr. Scott's route to academic prominence would be considered remarkable by today's standards. He was the youngest of six children, educated in a one-room schoolhouse in Southwestern Ontario. He quit school in grade 10, after the death of his father, to help raise the family. He joined the Royal Canadian Air Force as a teenager and served four years overseas in World War II. After returning to Canada, Arthur completed high school and attended the University of Toronto Medical School. Following ten years in family practice in Sault St. Marie, he returned to Toronto to complete his residency in Anesthesia. Arthur practiced clinical anesthesia at the Toronto General Hospital (TGH) and became Director of the Respiratory Intensive Care Unit and Chief of its Department of Anesthesia.

Arthur served as the Chair of the University of Toronto Department of Anesthesia (1977-87) and later as VicePresident Medical Affairs at TGH. During this time, one colleague recalls that he was impressed with Arthur's organization and thoroughness, as well as his perpetual smile and reassuring presence in his work. After retirement, Dr. Scott reflected on his philosophy and time as Chair in a monograph ${ }^{1}$ to commemorate the 50-year anniversary of the Department. He noted that when he

R. Byrick, MD ( $\square)$

University of Toronto, Toronto, ON, Canada

e-mail: robert.byrick@utoronto.ca began practice, the specialty was "still evolving from its fledgling beginnings" and, similar to today, was "faced with critical staff shortages". ${ }^{1}$ His answer to this urgency showed foresight as a leader and insight into system-wide solutions. He conducted the first province-wide manpower study, expanded anesthesia's role in undergraduate education, and influenced the Ontario Ministry of Health to expand training programs (including critical care

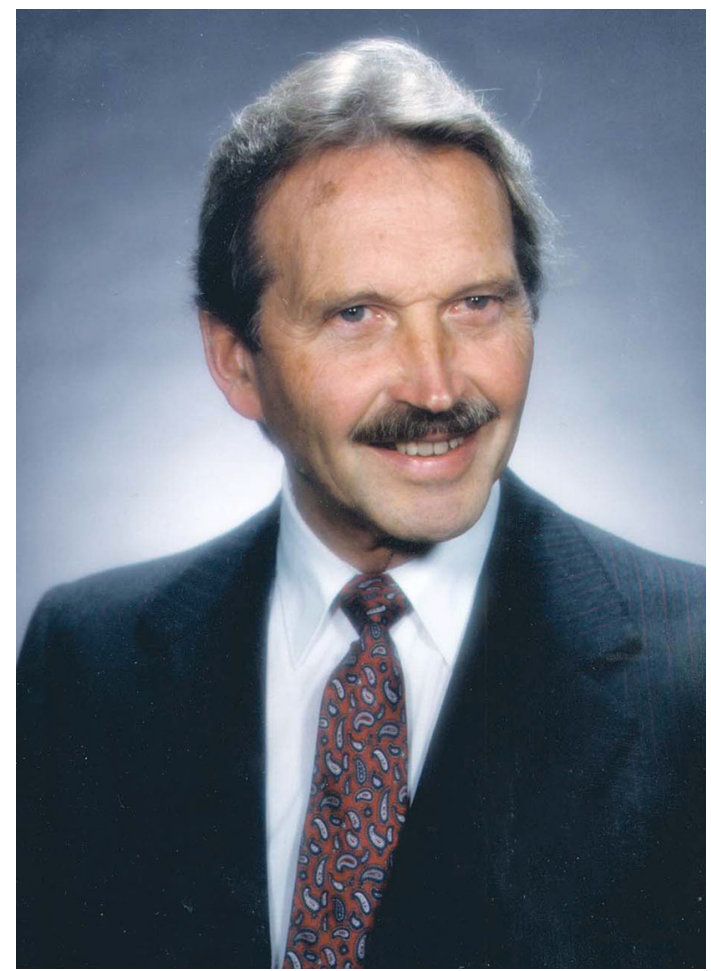

Figure Arthur A. Scott, MD, FRCPC (1923-2018). Reproduced with permission. ${ }^{1}$ 
positions for anesthesiologists and a family practice anesthesia program). He re-organized the academic department and encouraged research as well as education. He foresaw the need for respiratory therapists as allied healthcare providers and became Chair of the Board of the Toronto Institute of Medical Technology.

In his reflections on his time at the University of Toronto, he recognized that "our accomplishments in anaesthesia would not be possible without the work of those physicians who came before us". ${ }^{1}$ He further noted that "our discipline's progress is built on the achievements of those in the past and will be improved upon by the enthusiasm and perseverance of those yet to come". 1

Dr. Scott is remembered for his friendship and encouragement to those who met him. He was a gentleman and leader, whose enthusiasm and perseverance contributed in a meaningful way to our discipline's progress. A memorial donation to recognize
Arthur's contributions to the profession may be made to the Department of Anesthesia, University of Toronto, at 123 Edward St., Suite 1201, Toronto, Ontario M5G 1E2 (businessmanager.anesthesia@utoronto.ca).

Conflicts of interest None declared.

Editorial responsibility This submission was handled by Dr. Hilary P. Grocott, Editor-in-Chief, Canadian Journal of Anesthesia.

\section{Reference}

1. Scott AA. Reflections on a decade as chair. In: Byrick RJ (Editor); Bevan JC, McKnight DJ (Associate Editors). A Commemorative History of the Department of Anaesthesia. University of Toronto. Department of Anaesthesia, University of Toronto; 2004: 277-88. 